\title{
Notas sobre o politicamente correto
}

\author{
Notes on political correctness
}

\section{Apuntes sobre lo políticamente correcto}

\section{Amadeu de Oliveira Weinmann*}

Universidade Federal do Rio Grande do Sul - UFRGS, Porto Alegre, Rio Grande do Sul, Brasil

\section{Fábio Vacaro Culau**}

Universidade Federal do Rio Grande do Sul - UFRGS, Porto Alegre, Rio Grande do Sul, Brasil

\begin{abstract}
RESUMO
O artigo propõe-se a retomar o debate acerca do politicamente correto (PC), pois considera esse tema relevante no que concerne às lutas em torno da constituição do sujeito contemporâneo. Nesse sentido, examina as principais críticas endereçadas ao PC pelos autores revisados, a fim de detectar 0 estado atual dessa discussão. Em seguida, detém-se sobre as relações do PC com o humor, tomando como referência conceitual as elaborações freudianas sobre esse assunto. Por fim, analisa algumas das condições de formação dos discursos PC, a fim de realçar seus limites e possibilidades. A hipótese deste trabalho é a de que, tanto no que tange a suas premissas teóricas, quanto no que diz respeito a suas estratégias de intervenção, é possível - e desejável - reinventar o PC.
\end{abstract}

Palavras-chave: politicamente correto, humor, Freud.

\section{ABSTRACT}

The article seeks to resume the debate on political correctness (PC), since this is a central issue concerning the struggle over the constitution of the contemporary subject. In this sense, it examines the main criticisms addressed to PC by the reviewed authors, so as to give an account of the current state of this discussion. Following, it focus on the relationship between PC and humor, taking Freudian conceptual elaboration as a reference on the matter. Finally, it analyses some of the conditions for the formation of PC discourse, in order to highlight its limits and possibilities. The hypothesis of this work is that, as much in terms of its theoretical premises as in what concerns its intervention strategies, it is possible - and desirable - to reinvent PC.

Keywords: political correctness, humor, Freud.

\section{RESUMEN}

El artículo se propone a retomar el debate respecto a lo políticamente correcto ( $\mathrm{PC})$, considerándolo un tema relevante en lo que concierne a las luchas en la constitución del sujeto contemporáneo. En ese sentido, examina 
las principales críticas dirigidas a lo PC por los autores revisados, con el fin de detectar el estado actual de esa discusión. En seguida se detiene sobre las relaciones de lo PC con el humor, tomando como referencia conceptual las elaboraciones de Freud sobre ese tema. Por último, analiza algunas de las condiciones de formación de los discursos PC, con el fin de destacar sus límites y posibilidades. La hipótesis de este trabajo es la de que, tanto en relación a sus supuestos teóricos, como respecto a sus estrategias de intervención, es posible - y deseable - reinventar lo PC.

Palabras clave: políticamente correcto, humor, Freud.

\section{I ntrodução}

Por que retomar o debate acerca do politicamente correto? Ele não está esgotado? Parece-nos que não. Se admitimos, em Psicologia, a premissa de que um sujeito delineia-se a partir das práticas discursivas que o nomeiam, somos levados a conceber o PC como parte de uma agonística constitutiva de importantes aspectos da subjetividade contemporânea. A partir da revisão bibliográfica realizada, este artigo destaca três momentos em que essa discussão foi particularmente intensa em nosso país. Nos anos 1990, a introdução dessa questão suscita intervenções de intelectuais tanto na imprensa, quanto na atividade acadêmica. Em artigo à Folha de S. Paulo, o filósofo Renato Janine Ribeiro (1992) parece ter sido um dos primeiros a levantar o problema, mas entrevistas do filósofo Claude Lefort (como citado em Scalzo, 1994) e do crítico literário Harold Bloom (como citado em Nestrovski, 1995), dentre outras, indicam que o tema esteve em pauta na grande imprensa. Paralelamente, no âmbito acadêmico a linguagem politicamente correta é alvo de acalorados debates, como demonstram os trabalhos de Possenti (1995), Borges (1996), Soares (1998) e Rajagopalan (2000).

Em 2004, um documento do governo federal - Politicamente correto e direitos humanos - reacende uma polêmica que parecia extinta. No entanto, se nos anos 1990 a polarização é uma marca da discussão desse tema, em meados da primeira década do século XXI os argumentos tendem a situar-se quase inteiramente do lado da desqualificação do PC. Na grande imprensa, as matérias de Lima (2005), Redação Terra (2005) e Schwartsman (2005), dentre outras, testemunham a posição hegemônica contrária ao controle da linguagem proposto pela cartilha do governo. Paradoxalmente, uma matéria da revista Exame - "Na mira do politicamente correto" -, também de 2005, mostra a enorme influência da pressão de grupos organizados sobre o comportamento de grandes empresas.

Em 2009, o lançamento do livro Guia politicamente incorreto da história do Brasil, do jornalista Leandro Narloch, obtém estrondoso sucesso, indicando haver um público ávido por ridicularizar as teses PC - e não muito preocupado com rigor metodológico. Explorando o 
filão recém descoberto, a editora Leya também publica o Guia politicamente incorreto da América Latina, dos jornalistas Leandro Narloch e Duda Teixeira, em 2011, e o Guia politicamente incorreto da filosofia, do filósofo Luiz Felipe Pondé, em 2012. Nesse cenário de demolição dos discursos PC, dissemina-se uma modalidade de humor que tem como critério de avaliação o aplauso de sua platéia, como lei, a lei da oferta e da procura, e como fonte de preconceitos firmemente enraizados em nossa cultura. Em 2012, o lançamento do documentário $\mathrm{O}$ riso dos outros, do diretor Pedro Arantes, consiste em um ponto de inflexão dessa tendência, na medida em que interroga acerca dos limites do humor. É este modo de abordar o problema do politicamente incorreto que nos incita a escrever sobre esse tema.

$\mathrm{Na}$ construção deste artigo, adotamos os seguintes procedimentos metodológicos. Inicialmente, procuramos delimitar, conceitualmente - ainda que de forma provisória -, o que entendemos por PC. Ato contínuo, ocupamo-nos das três principais críticas endereçadas ao PC por alguns dos trabalhos revisados: 1) o PC é equivocado, em termos linguísticos, na medida em que pressupõe uma relação unívoca entre a palavra e seu referente; 2) o PC é politicamente ingênuo, pois pretende resolver o problema das relações sociais discriminatórias por meio da mudança de palavras; e 3) o PC possui uma vocação autoritária, uma vez que acarreta a restrição da liberdade de expressão. A análise dessas críticas mostra que a questão é muito mais complexa do que as abordagens do tema, geralmente maniqueístas, costumam apontar.

Dito isso, embarcamos na reflexão acerca dos limites do humor, proposta pelo documentário $\mathrm{O}$ riso dos outros. A fim de conceder um estatuto conceitual a esse tema, recorremos às teses freudianas formuladas em Os chistes e sua relação com o inconsciente, de 1905, e em O humor, de 1927. Para Freud, chiste e humor consistem em modalidades do cômico e pressupõem um trabalho psíquico, isto é, têm como premissa que um sujeito interrogue-se acerca de sua condição e reposicione-se diante dela. Afinal, a graça está em escapar, ainda que por um instante fugaz, de uma situação de assujeitamento. Evidentemente, essa é uma abordagem ética do problema. A partir dela, a questão dos limites do humor coloca-se para um sujeito por meio da pergunta: de que modo te implicas na piada que fazes? Ou, como pontua Soares (1998, p. 324): “o humor mais correto, politicamente, é aquele mais refinado, em que não há restrições à fala, mas sofisticação na escuta".

Por fim, procuramos analisar algumas das condições de formação dos discursos PC. Por meio desse enfoque, objetivamos realçar tanto os limites que os circunscrevem, quanto às possibilidades que a eles se oferecem. Nesse sentido, situamos o advento do PC no ponto de convergência entre o aparecimento dos movimentos de defesa dos 
direitos civis e o declínio do comunismo, isto é, o vinculamos à constituição de uma nova esquerda. Ademais, reconhecemos a relevância do fato, destacado por muitos autores, do PC haver nascido nos EUA. Entretanto, notamos a ausência de referências com a honrosa exceção de Rajagopalan (2000) - à filiação do PC ao que se denomina virada linguística, ou seja, à concepção de que o modo como nomeamos o mundo é constitutivo da experiência que dele fazemos. É no entrecruzamento desses processos, que floresce o PC. Por esse motivo, consideramos reducionista a apresentação dessa discursividade que emerge das críticas mencionadas acima. A hipótese deste trabalho é a de que, tanto no que concerne a suas premissas teóricas, quanto no que tange a suas estratégias de intervenção, o PC é permeável à invenção.

\section{Delimitando o politicamente correto}

Politicamente correto é uma daquelas expressões que, de tão enraizadas no senso comum, tornam-se difíceis de delimitar, conceitualmente. Mesmo em trabalhos acadêmicos, é frequente encontrar abordagens desse tema que pressupõem que seu objeto é evidente, razão pela qual não realizam a operação de enunciar o que entendem por PC. Neste artigo, adotamos o ponto de vista, implícito em quase todos os trabalhos revisados, de que o PC consiste em um conjunto de intervenções políticas - visto que exercem pressão contra práticas ditas de assujeitamento -, cujo alvo preferencial é a linguagem ou, mais precisamente, determinadas manifestações linguísticas, que carregariam em si a marca da discriminação contra grupos minoritários. De acordo com essa perspectiva, as condições de aparecimento do PC estariam ligadas aos movimentos em favor dos direitos civis, nos EUA dos anos 1960, e aos enfoques multiculturalistas, que se disseminam nos anos 1980 nas universidades norteamericanas na esteira daqueles movimentos e que têm como mote a crítica da subjetividade padrão, qual seja: o homem branco, heterossexual e burguês (Rodden, 2010).

\section{Uma linguagem politicamente correta?}

Em 2004, a Secretaria Especial de Direitos Humanos da Presidência da República do Brasil lança o documento Politicamente correto e direitos humanos. Na sua apresentação, a cartilha do politicamente correto (como passou a ser conhecido o documento) propõe-se a chamar a atenção da sociedade para uma série de expressões que, embora de uso corriqueiro - e, talvez, precisamente por isso -, destilam preconceitos, sem que necessariamente tomemos 
consciência disso. Ao longo do texto, noventa e seis expressões são comentadas, dentre elas: anão, beata, denegrir, funcionário público, judiar e vadia. A fim de mostrar ao leitor o modo como procede o documento, citamos um exemplo: "a coisa ficou preta - a frase é utilizada para expressar o aumento das dificuldades de determinada situação, traindo forte conotação racista contra os negros" (Queiroz, 2004). No entanto, apesar de pretender contribuir para a construção de uma cultura de direitos humanos no país, a cartilha é duramente criticada por escritores, acadêmicos, imprensa e, inclusive, por setores do Governo, vindo a ter sua distribuição suspensa.

Afinal, qual o problema do PC? Assumindo que essa formação discursiva tem como objetivo estratégico intervir sobre a linguagem cotidiana, a fim de desfazer efeitos de assujeitamento que nela se encontram cristalizados, esta seção orienta-se pelas seguintes perguntas, extraídas da revisão bibliográfica realizada: 1) que vínculos existem entre práticas discursivas e relações sociais? Em outras palavras, intervindo-se sobre as primeiras altera-se as de o fundador da psicanálise não ter se debruçado sobre essa situação. O humor, segundo pensamento freudiano, implica, por um lado, o reconhecimento de uma condição de alienação e, por outro, um trabalho sobre si próprio. No que canto, implica uma inibição do pensamento? Entendemos que abordar a questão a partir dessas perspectivas permite ir além da polarização passional, que tem caracterizado o debate acerca do PC.

Em A linguagem politicamente correta e análise do discurso, Possenti (1995) pesquisa os fatos discursivos produzidos pelo PC, a partir da premissa de que a materialidade de um signo não carrega, em si, sua significação, tampouco esta advém das intenções do locutor. De acordo com esse linguista, o sentido de um enunciado é dado pela trama de relações que configura um discurso, a qual é historicamente determinada. No entanto, o autor enfatiza que os discursos não refletem as relações sociais, mas as refratam, visto que os enunciados são objeto de uma permanente disputa. No que concerne ao PC, Possenti observa que sua estratégia predominante é a de substituir palavras marcadas por outras, que supostamente seriam neutras. Para o linguista, tal procedimento implica duas premissas: 1) as palavras possuem um sentido essencial; 2) mudando-se as palavras, transformam-se as relações sociais. No que diz respeito ao primeiro ponto, Possenti (1995) comenta o debate em torno do termo mulato, supostamente derivado de mula - motivo de ser considerado discriminatório. O autor observa que o recurso à etimologia, visando desvendar o sentido irredutível de uma expressão, é capcioso. No caso da palavra mulato, é possível postular que ela deriva do vocábulo árabe mohalát, que significa mestiço. I sso apenas mostra que a origem de determinado termo - lugar onde repousaria sua suposta essência - é perdida ou mítica. 
Em decorrência da afirmação de que o sentido de uma palavra não Ihe é intrínseco, mas lhe é dado pela trama discursiva em que ela se encontra, trama essa que lança raízes em determinado caldo de cultura, Possenti (1995) questiona a estratégia de combate aos preconceitos por meio da mudança de palavras. De acordo com o linguista, é a existência de situações de discriminação social que carrega certas expressões com seus efeitos de sentido, "embora não se possa desprezar o fato de que o discurso pode servir para realimentar as condições sociais que dão suporte às ideologias" ( $p$. 138). Assim, substituir termos marcados por eufemismos - portador de necessidades especiais, em vez de aleijado -, ou por definições descritivas - prestadora de serviços sexuais, em vez de prostituta apenas transportaria as conotações depreciativas de uma expressão para sua substituta.

Em A busca do inencontrável: uma missão politicamente (in)correta, Borges (1996) sublinha o caráter maniqueísta dos discursos PC, impresso na dicotomia correto-incorreto e na concepção de que há expressões intrinsecamente preconceituosas e outras, não. De acordo com o linguista, em tal conceito de linguagem está implícita a tese de que esta reflete, em vez de refratar, determinadas condições sociais. Dito de outro modo, para o PC as palavras seriam transparentes e revelariam sua significação de forma cristalina. Assim, se considera ingênua a concepção linguística do PC, e Borges (1996) também considera inócua sua estratégia de intervenção, e isso porque tal modalidade de atuação política não alteraria os fatores sóciohistóricos, que constituem as condições extralinguísticas de produção dos discursos. Apesar de reconhecer que "as palavras têm sua cota evidente de contribuição para a instituição da realidade tal qual a representamos" (p. 111), o linguista sustenta que "[...] será tãosomente ao atingir o nível das estruturas formadoras da sociedade que, de fato, poderão ocorrer alterações nas práticas e nas relações sociais visíveis" (p. 111).

Em Sobre o porquê de tanto ódio contra a linguagem "politicamente correta", Rajagopalan (2000) diverge de linguistas como Possenti e Borges no que diz respeito aos laços que se constituem entre linguagem e relações sociais. Para esses teóricos da Análise do Discurso, as intervenções do PC não afetam o magma das significações, ou seja, as estruturas formadoras da sociedade retomando a expressão de Borges (1996), citada acima - que permitem compreender o caráter ideológico da linguagem: "as formas linguísticas [...] reproduzem uma ideologia que segrega em termos de classe, sexo, raça e outras características físicas e sociais objeto de discriminação" (Possenti, 1995, p. 125). Se, por um lado, essa articulação entre materialismo histórico e linguística - o signo linguístico é a materialidade do ideológico, diz Borges (1996) sustenta o postulado de que nenhuma palavra é pura, neutra, 
inocente, visto que sua significação depende das condições históricas de sua enunciação, por outro, tal constructo implica a determinação em última instância, como requer a tradição marxista - da linguagem pelas relações sociais.

Em contrapartida, Rajagopalan (2000, p. 102) pensa o laço entre práticas discursivas e sociedade em termos de imanência: "intervir na linguagem significa intervir no mundo". De acordo com esse linguista, a crítica à estratégia de intervenção do PC funda-se na concepção de uma radical distinção entre realidade e linguagem, concepção essa que atribui ao discurso uma função de representação. Para tal enfoque linguístico, é quixotesco atacar os representantes e manter intacto o universo representado. Em franca oposição a esse ponto de vista, Rajagopalan (2000) postula a indissociabilidade entre a palavra e seu referente. Para o autor, o objeto está imbricado em seu modo de apresentação. Portanto, uma mudança linguística acarreta a aparição de algo novo. No entanto, Rajagopalan (2000) parece desconhecer que a crítica de linguistas como Possenti (1995) e Borges (1996) ao PC também inclui a observação do caráter unívoco da relação entre palavra e sentido, efetuada por esses discursos.

Por fim, uma questão que permeia esse debate é: as intervenções do PC sobre a linguagem cotidiana constituem uma modalidade de censura? No que tange a esse assunto, Possenti (1995) assinala dois possíveis efeitos nefastos do PC: o cerceamento da liberdade de expressão e o empobrecimento das línguas. Por sua vez, Borges (1996, p. 115) interroga: "será doravante este o valor intrínseco pelo qual as obras de arte deverão ser apreciadas? Se for sim, [...] o acervo artístico da humanidade será reduzido, em sua maioria, a atentados ao politicamente correto". Em entrevista à Folha de S. Paulo, o crítico literário Harold Bloom (como citado em Nestrovski, 1995, p. 5-5) observa, ironicamente, que nas universidades norteamericanas o critério de valor de uma obra resume-se às perguntas: "a autora é mulher? O autor é americano-asiático ou americano-'nativo'?". Rodden (2010, p. 3) é ainda mais duro com o multiculturalismo, um dos fundamentos teóricos do PC:

Multiculturalismo na universidade americana é o fundamentalismo da esquerda. Em suas versões extremistas, representa uma ortodoxia tão dogmática quanto o chamado islamofascismo, isto é, o dogma daqueles grupos terroristas árabes que invocam a bandeira protetora do Islã para justificar seus atos de violência.

Em contrapartida, Renato Janine Ribeiro (1992, 5-3) problematiza o que se denomina patrulha PC: 
Antes de mais nada evitemos, contra o "patrulhamento" do PC, tomar defesa dos produtos da indústria cultural. Quem, em sã consciência, pode dizer que esta se distingue pela liberdade de criação? Décadas a fio, Hollywood se conformou ao código Hayes, que proibia beijos de mais de três segundos e difundiu pelo mundo a impressão de que os casais americanos dormiam em camas separadas... As séries de TV americanas são fruto de inúmeras injunções econômicas, sociais, políticas; a própria presença de negros nelas é conquista de movimentos raciais. Assim, que minorias examinem com a lupa roteiros e programas para reclamar de termos preconceituosos não significa que alguma censura "esquerdista" venha massacrar obras-primas criadas em plena liberdade. Não são obrasprimas, não foram criadas sem pressão, nem a crítica a elas é esquerdista.

De acordo com o filósofo, a antipatia em relação ao PC, inclusive entre acadêmicos, decorre sobretudo do fato de o PC consistir em um efeito da organização de minorias contra atitudes discriminatórias profundamente arraigadas em nossa cultura.

Em sintonia com Ribeiro, Luiz Eduardo Soares (1998) vincula a repulsa ao PC à atitude misógina, racista e homofóbica da sociedade brasileira. De acordo com esse antropólogo, no que tange ao PC a elite nacional oscila entre três posições:

(1) "trata-se de manifestação do histerismo fanático norteamericano, que castra o humor, mata a espontaneidade humana e disciplina todas as relações interpessoais"; (2) "trata-se de manifestação de intolerância de inspiração puritana e conservadora, que enseja a produção de identidades sociais artificialmente depuradas de qualquer carga de ambivalência, expressando uma cultura fortemente racionalista e autoritária"; (3) "trata-se do nome dado a uma pretensão equivocada e perigosa, no limite totalitária, de definir uma gramática unívoca do comportamento socialmente aceitável" (p. 220).

Em contrapartida, o autor insere o PC na tradição denominada por Norbert Elias de processo civilizador. Nessa perspectiva, o que tal discursividade promove é uma ética micropolítica do cotidiano, assentada na regulação das diferenças e na contenção da violência, visando uma sociabilidade efetivamente democrática.

A partir das formulações acima, pensamos ser possível afirmar a complexidade do debate acerca do PC. Mesmo críticos ácidos dessa orientação discursiva, como Borges (1996, p. 112), reconhecem suas virtudes: "[...] o movimento pelo politicamente correto pode oferecer uma contribuição relevante, ao tornar visíveis comportamentos e 
atitudes impregnados de preconceitos, os quais, via de regra, passam por naturais e 'inocentes'". Por outro lado, um defensor ardoroso do PC, como Rajagopalan (2000, p. 101), também reconhece seus limites: “[...] a linguagem politicamente correta não é nenhum remédio milagroso contra os preconceitos que estão fortemente arraigados em nossa sociedade". A fim de desdobrar essas análises, na próxima seção discutiremos a relação do PC com um campo particularmente sensível: o do humor.

\section{Um humor politicamente correto?}

Em 2011, algumas declarações supostamente humorísticas do comediante Rafinha Bastos reacenderam a polêmica em torno dos limites do humor. No documentário $\mathrm{O}$ riso dos outros, o diretor Pedro Arantes (2012) dá voz - e imagem - a esse debate. Com o intuito de deflagrar a reflexão proposta nesta seção, destacamos alguns pontos deste trabalho. Laerte (como citado em Arantes, 2012) observa que o humor envolve certa dose de crueldade. Nesse sentido, sempre haverá alguém ofendido por uma piada. Porém, o cartunista ressalva: a questão é como essa ofensa é negociada, historicamente. O ensaísta Delber Avelar (como citado em Arantes, 2012) assinala que a piada preconceituosa é a mais fácil, pois se assenta em noções naturalizadas. Difícil é desmontar os estereótipos. A militante feminista Renata Moreno (como citado em Arantes, 2012) afirma que, se alguém é livre para dizer que mulher feia estuprada deve agradecer, é porque não há constrangimento social à prática do estupro. O militante LGBT Jean Wyllys (como citado em Arantes, 2012) (como citado em Arantes, 2012) aponta a contradição dos que reivindicam liberdade de expressão, mas não toleram contestações. 0 produtor de stand up comedy Gabriel Grosvald (como citado em Arantes, 2012) salienta que o humor que Ihe interessa é o que ri do carrasco, não da vítima.

Em contrapartida, o comediante Alysson Vilela (como citado em Arantes, 2012) diz sentir-se amordaçado pelos discursos PC. O apresentador de TV Danilo Gentili (como citado em Arantes, 2012) fala em patrulhamento e observa que sua pretensão não é denunciar, mas destruir. Rafinha Bastos (como citado em Arantes, 2012) afirma que a censura está de volta e que não Ihe interessa teorizar acerca da função social do humor. A comediante Marcela Leal (como citado em Arantes, 2012) postula que não tem que ser responsabilizada pelo que fala, pois sua função é apenas divertir. Maurício Meireles (como citado em Arantes, 2012) sublinha que piada não é opinião e, em contraposição aos que dizem que o PC inibe o pensamento, observa, estupefato, que o humorista agora vai ter que pensar. Em distintos depoimentos atribui-se à plateia a atitude preconceituosa, pois é ela 
quem ri das piadas. Ao comediante caberia somente encontrar o tema que a faz gozar, sem questionar-se.

É intrigante observar o apoio, ainda que indireto, às teses dos adeptos do politicamente incorreto por parte de psicanalistas. Mapurunga e Carneiro (2011) interrogam se a linguagem PC é capaz de impedir o ódio - sentimento politicamente incorreto, por excelência - de expressar-se no laço social. Na perspectiva desses autores, o que o PC produz é um recalque da violência contemporânea, a qual retorna com ainda maior virulência, visto que, colocar o ódio em palavras é um modo do sujeito esquivar-se do ato destrutivo. No tocante a esse problema, Koltai (2012, p. 41) acrescenta:

Em tempos do politicamente correto, [...] o analista precisa ousar ser politicamente incorreto já que sua função não pode ser nem a de criar vítimas, nem a de manter o sujeito nessa posição a vida inteira e sim fazê-lo pensar e se implicar no que Ihe acontece, por mais que o modelo sustentado por nossa sociedade aja no sentido da des-responsabilização do sujeito, atribuindo [...] tudo que acontece ao sujeito a determinantes externos.

Nesse sentido, o PC incorreria em um duplo equívoco: por um lado, bloquearia um importante meio de regulação do ódio nas relações sociais e, por outro, cristalizaria determinados sujeitos na posição de vítimas.

Porém, o que diria sobre esse tema o fundador da psicanálise? Em Os chistes e sua relação com o inconsciente, Freud (1996a) sugere que um chiste envolve três sujeitos: aquele em quem ele se forma, um objeto e um público. Além disso, o autor descreve quatro modalidades de chistes: os obscenos, os hostis, os cínicos e os céticos. Embora os chistes mencionados por Freud ofereçam-se a nossa apreciação desprovidos de um aspecto crucial - a atualidade -, lançamos mão deles por sua excelência. No chiste obsceno, uma gratificação erótica é visada. Ao dizer "essa garota me lembra Dreyfus. O exército inteiro não acredita em sua inocência" (p. 47), um sujeito goza com a moça por meio do chiste, em vez de fazê-lo do modo como supostamente o realizaram os soldados. No chiste hostil, o ódio satisfaz-se. Ao referir-se a um jovem descendente ruivo de Jean-Jacques Rousseau como roux et sot (ruivo e tolo), a dama parisiense aproveita-se da homofonia para destilar toda sua decepção com o rapaz.

Nessas duas modalidades de chiste, o prazer parece derivar diretamente de moções pulsionais. No que concerne às outras duas, a situação é mais complexa. Freud (1996a) denomina chistes cínicos os que afrontam uma instituição. Quando um príncipe pergunta a um 
rapaz, cuja semelhança consigo the impressiona, se sua mãe frequentou o palácio, trata-se de um chiste hostil. Porém, quando o rapaz responde que sua mãe não, mas seu pai sim, não se trata de sublimar a agressão apenas por consideração a uma regra moral, mas também devido ao poder da instituição monárquica. Um ótimo chiste desse tipo é do próprio Freud. Instado a pronunciar-se sobre a queima de seus livros pelos nazistas, o psicanalista saiu-se com essa pérola, ademais profética: "que progressos estamos fazendo [...]. Na Idade Média, teriam queimado a mim; hoje em dia, eles se contentam em queimar meus livros" (como citado em Gay, 1989, p. 536). No que diz respeito aos chistes céticos, seu alvo é a verdade, tal como esta é compartilhada em determinado contexto cultural. Nesse sentido, os chistes cínicos e céticos podem ser considerados subgrupos dos chistes hostis.

No entanto, Freud (1996a) não atribui o prazer produzido por um chiste apenas à gratificação de determinadas moções pulsionais. Se assim fosse, cairia por terra a distinção entre chiste e insulto. Para o instaurador do discurso analítico, o chiste tem parentesco com o sonho, isto é, consiste em uma formação do inconsciente. Em outras palavras, em sua elaboração um chiste compartilha com os sonhos algumas de suas técnicas. Um dito cai no pré-consciente e ali permanece, exigindo um trabalho psíquico. Ato contínuo, é lançado rumo ao inconsciente, onde é remodelado de acordo com um desejo, por meio das técnicas de condensação e deslocamento. Por fim, tal dito é devolvido à esfera social, de um modo que sua natureza chistosa possa ser desfrutada por um interlocutor cúmplice. É nesse terceiro momento que se diferenciam sonho e chiste, pois no processo onírico o pensamento inconsciente é arremetido ao sistema sensorial - técnica da figurabilidade, específica do sonho - e retorna para o sujeito sob a forma de imagens fragmentadas e absurdas. De acordo com essa conceitualização, o prazer do chiste decorre de uma superação, ainda que transitória, da resistência de um sujeito em admitir um desejo - o qual se realiza por meio do jogo lúdico com palavras e pensamentos, que forma um chiste.

Em O humor, Freud (1996c) retoma esse tema. Para o psicanalista, o humor sempre tem um objeto, que pode ser o próprio sujeito ou outro, e um espectador. No que tange a este, seu prazer é derivado. Portanto, é preciso estudar a dinâmica psíquica do humorista. Com esse fim em vista, Freud (1996c) toma como ponto de partida o comentário de um criminoso a caminho da forca, em uma segundafeira: "bem, a semana está começando otimamente!" (p. 165). Tal observação é inusitada. No que ela se sustenta? Freud a atribui a duas características do humor. Por um lado, ele é onipotente, isto é, decorre do triunfo do eu sobre a realidade. Por outro, o humor voltado para os outros mostra que ele infantiliza seu objeto. Nesse sentido, como compreender que alguém possa rir de sua desgraça? 
Freud (1996c)propõe que o supereu é o herdeiro da instância parental e que ele trata ao eu com a benevolência e a severidade de um pai. Assim, a atitude humorística de um sujeito diante de uma situação difícil expressa uma mensagem do supereu protetor a um eu amedrontado: “olhem! Aqui está o mundo, que parece tão perigoso! Não passa de um jogo de crianças, digno apenas de que sobre ele se faça uma pilhéria" (p. 169).

A partir dessas formulações, podemos retomar nossas reflexões acerca das relações entre o humor e o politicamente correto. Parecenos que os trabalhos de Freud sobre o chiste e o humor são indissociáveis de suas concepções sobre a articulação entre cultura e pulsão. Nesse sentido, o livro dos chistes deve ser lido, retrospectivamente, à luz de Moral sexual 'civilizada' e doença nervosa moderna e o artigo sobre o humor, sob a ótica de $\mathrm{O}$ mal estar na civilização. Na perspectiva de uma cultura que sufoca a gratificação pulsional, o chiste é uma sofisticada criação de um sujeito, a qual lança mão da atividade infantil de brincar com as palavras. Sob o viés da inevitabilidade do mal-estar, um supereu benevolente torna suportável a existência. Dito de outra forma, chiste e humor consistem, na teoria freudiana, em modos de um sujeito encontrar graça na vida, a despeito das limitações que a cultura lhe impõe, por meio de um trabalho psíquico liberador.

Se adotamos o enfoque freudiano, podemos sustentar que o humor consiste em um modo do sujeito resistir ao assujeitamento: "o humor não é resignado, mas rebelde", diz Freud (1996c, p. 191). Porém, o que dizer do humor que toma o outro como objeto, muitas vezes de uma forma que, em vez de remeter a um supereu benevolente, parece constituir-se na expressão de um supereu sádico, cruel? Talvez não seja casualidade o fato de o fundador da psicanálise não ter se debruçado sobre essa situação. O humor, segundo pensamento freudiano, implica, por um lado, o reconhecimento de uma condição de alienação e, por outro, um trabalho sobre si próprio. No que concerne aos chistes, eles frequentemente são tendenciosos, isto é, ferem a outro sujeito, como nos exemplos mencionados acima. No entanto, parece-nos que a tônica freudiana incide sobre o que um chiste revela acerca de quem o enuncia. Por esse motivo, Freud (1996a) insiste que ninguém faz chistes sobre judeus melhor do que os próprios judeus. Em termos metapsicológicos, a piada discriminatória - misógina, racista, homofóbica, dentre outras parece pender muito mais para o lado do insulto.

\section{Reinventar o politicamente correto}

As condições de formação dos discursos PC são múltiplas. Bizzocchi (2008) salienta sua inscrição na tradição dos Direitos Humanos, que 
remonta ao lluminismo e à Revolução Francesa, adquire proeminência após a experiência do Holocausto (a Declaração Universal dos Direitos Humanos, da ONU, é de 1948) e explode como problemática social candente com os movimentos pelos direitos civis nos EUA, na década de 1960. O filósofo Vladimir Volkoff (como citado em Bizzocchi, 2008) vincula o PC à desintegração do comunismo: "se compararmos a demolição do comunismo com uma explosão atômica, diremos que o politicamente correto constitui a nuvem radioativa que acompanha a hecatombe". Pondé (2012, p. 30) também adota essa perspectiva:

"a diferença entre a velha esquerda e a nova esquerda é que, para a velha, a classe que salvaria o mundo seria o proletariado (os pobres), enquanto, para a nova, é todo tipo de grupos de 'excluídos': mulheres, negros, gays [...]".

Além disso, diversos autores (Possenti, 1995; Borges, 1996; Soares, 1998; Bizzocchi, 2008; Rodden, 2010; O' Neill, 2011; Pondé, 2012) destacam o fato do PC ter surgido nos EUA. Para alguns, o solo cultural de seu nascimento teria deixado marcas indeléveis em seu destino. De acordo com Ribeiro (1992, p. 5-3), o PC exibe “[...] um traço tipicamente americano, que é o do lobby. A sociedade americana perdeu há muito a noção de um espaço público, em que se discutem políticas amplas e gerais, a opinião lá se dissolveu numa infinidade de pequenos interesses locais ou setoriais". O filósofo Claude Lefort (como citado em Scalzo, 1994, p. 6-9) vai ainda mais longe: para ele, o PC "é um fenômeno americano, anglo-saxônico, que é insuportável, mas que é interessante na medida em que parece traduzir algo de muito antigo em uma certa tradição de seita nos Estados Unidos".

No entanto, entendemos que há outro processo crucial na irrupção dos discursos PC. Trata-se do que se denomina virada linguística, a qual tem em As palavras e as coisas - livro publicado por Foucault, em 1966 - um marco. Nessa obra, o filósofo analisa a radical transformação das ciências humanas, a partir do momento em que foram atravessadas pela linguística estruturalista. Sucintamente, é a filosofia da representação, isto é, a premissa de que a linguagem representa a realidade, o que é posto em questão. De acordo com a concepção emergente, a linguagem consiste no a priori, a partir do qual construímos a realidade. Em outras palavras, o que denominamos realidade consiste em uma convenção, a qual se ordena por regras discursivas que, em larga medida, nos são inconscientes - e esse é o tributo que Foucault presta a Freud, por haver colocado a linguagem no cerne de sua reflexão sobre o sujeito moderno. 
Porém, a filiação do PC à virada linguística, sugerida por Rajagopalan (2000), parece-nos idiossincrática. A tendência a estabelecer uma relação unívoca entre significante - entendido como a materialidade sensorial do signo - e significado, criticada por Possenti (1995), não consiste em uma característica típica de seitas, conforme indicado por Lefort (como citado em Scalzo, 1994)? E a luta tenaz de algumas minorias organizadas, no sentido de exercer o controle da linguagem, que Borges (1996) combate, não evoca o comportamento de lobby, mencionado por Ribeiro (1992)? Seria o PC um filho bastardo das novas concepções linguísticas, nascido deformado por conta de suas relações de parentesco com outros aspectos da cultura norteamericana?

Pensamos que promover a colagem da discursividade politicamente correta a tal formulação consiste em incidir na relação unívoca entre significante e significado, que se atribui ao PC. Nesse sentido, estamos de acordo com Soares (1998, p. 235):

"Politicamente correto" não é uma coisa, uma substância, uma gramática autoritária e rígida, passível de descrição abstrata, ou uma nova ética. É o nome vago e controverso de um processo aberto, em construção, tenso e incerto, que funciona como uma gravitação sociológica, impelindo os indivíduos a constantes negociações e renegociações de sentidos e de valores.

Ademais, entendemos que as estratégias de intervenção do PC podem ser múltiplas, isto é, não se restringem à substituição de palavras. No âmbito deste trabalho, realçamos duas técnicas de resistência ao assujeitamento: brincar com as palavras, a fim de permitir a invenção de novos sentidos - própria ao chiste -, e rir da própria desgraça, característica do humor. Por meio delas, um sujeito pode pôr em questão sua alienação a práticas discursivas discriminatórias.

\section{Considerações finais}

As análises realizadas neste artigo autorizam-nos a tecer algumas considerações acerca do PC. Antes de tudo, sobressai-se o caráter passional do debate sobre esse tema, isto é, sua tendência a incorrer em abordagens maniqueístas. É quase como se fosse impossível pensar tal assunto. Além disso, da análise dos textos críticos ao PC depreende-se uma descrição desses discursos que flerta com a caricatura. A soldagem entre significante e significado, que se atribui ao PC e que consiste na mola mestra dos discursos discriminatórios, parece presidir o modo como se lê o politicamente correto (que 
adeptos também o façam não altera em nada a questão). Terá o debate em torno do PC herdado essa tendência dos discursos que ele combate?

A fim de esquivar-se dessa tendência, este artigo inspira-se no modo de problematizar 0 dito politicamente incorreto proposto pelo documentário $\mathrm{O}$ riso dos outros, isto é, aquele que interroga pelos seus limites. É essa forma de propor a questão que nos permite apostar no relançamento do debate acerca do PC, pois ela incita o pensamento. Neste trabalho, analisamos o problema dos limites do humor, à luz das elaborações freudianas sobre esse tema. Delas emerge uma concepção de humor, na qual um sujeito se implica na piada que faz. Para tal enfoque, a graça advém do reconhecimento e concomitante movimento de retirada - de uma posição de assujeitamento. Além disso, a teorização freudiana descreve técnicas que permitem a um sujeito pôr em questão sua alienação a discursos discriminatórios: o jogo lúdico com as palavras, que torna possível a invenção de novos sentidos - próprio ao chiste -, e o rir de sua desgraça, característico do humor. Por meio da exposição de tal concepção de humor e das técnicas que lhe concernem, pretendemos ter mostrado que o PC possui virtualidades, isto é, que é passível de reinvenção.

\section{Referências}

Arantes, P. (2012). O riso dos outros. São Paulo: Massa Real. Recuperado em 23 fevereiro, 2014, de: http://www.youtube.com/watch?feature=player_embedded $\& v=$ PRQ1LuBWoLg.

Bizzocchi, A. (2008, abril). É correto ser politicamente correto? [Versão eletrônica]. Revista língua portuguesa, 3 (30). Recuperado em 23 fevereiro, 2014, de: http://www. aldobizzocchi.com.br/artigo67.asp.

Borges, L. (1996). A busca do inencontrável: uma missão politicamente (in)correta. Cadernos de estudos lingüísticos, 31, 109-125.

Foucault, M. (2002). As palavras e as coisas (8a ed.). (S. T. Muchail, Trad.). São Paulo: Martins Fontes. (Obra original publicada em 1966).

Freud, S. (1996a). Os chistes e sua relação com o inconsciente. In S. Freud, Edição standard brasileira das obras psicológicas completas de Sigmund Freud (J. Salomão, Trad., Vol. 8, 3a ed., pp. 9-222). Rio de Janeiro: I mago. (Obra original publicada em 1905).

Freud, S. (1996b). Moral sexual 'civilizada' e doença nervosa moderna. In S. Freud, Edição standard brasileira das obras 
psicológicas completas de Sigmund Freud (J. Salomão, Trad., Vol. 9, 3a ed., pp. 165-186). Rio de Janeiro: Imago. (Obra original publicada em 1908).

Freud, S. (1996c). O humor. In S. Freud, Edição standard brasileira das obras psicológicas completas de Sigmund Freud (J. Salomão, Trad., Vol. 21, 3a ed., pp. 161-169). Rio de Janeiro: I mago. (Obra original publicada em 1927).

Freud, S. (1996d). O mal estar na civilização. In S. Freud, Edição standard brasileira das obras psicológicas completas de Sigmund Freud (J. Salomão, Trad., Vol. 21, 3a ed., pp. 65148). (J . Salomão, Trad.). Rio de Janeiro: Imago. (Obra original publicada em 1930).

Gay, P. (1989). Freud: uma vida para o nosso tempo (D. Bottmann, Trad.). São Paulo: Companhia das Letras. (Obra original publicada em 1988).

Koltai, C. (2012). O inconsciente seria politicamente incorreto? Reverso, 34(63), 33-44.

Lima, J. (2005, maio 11). Índex de palavras: cartilha politicamente correta do governo federal condena termos de uso comum entre escritores e compositores [Versão eletrônica]. Veja. Recuperado em 1 março, 2014, de: http://veja.abril.com.br/110505/p_141.html.

Luz, S. (2005, agosto 10). Na mira do politicamente correto [Versão eletrônica]. Exame. Recuperado em 23 fevereiro, 2014, de: http://exame.abril.com. br/revista-

exame/edicoes/0849/noticias/na-mira-do-politicamentecorreto-m0057099.

Mapurunga, J., \& Carneiro, H. (2011). O psicanaliticamente correto e o que é dito 'politicamente incorreto'. Anais do congresso $O$ psicanalista, sua clínica e sua cultura, Fortaleza, CE, Brasil. Recuperado em 23 fevereiro, 2014, de: http://www. psicanalise.ufc. br/hot-site/pdf/Trabalhos/42.pdf.

Narloch, L. (2009). Guia politicamente incorreto da história do Brasil. São Paulo: Leya.

Narloch, L., \& Teixeira, D. (2011). Guia politicamente incorreto da América Latina. São Paulo: Leya.

Nestrovski, A. (1995, agosto 6). Bloom contra-ataca [Versão eletrônica]. Folha de São Paulo - Mais!, pp. 5-4 - 5-7. Recuperado em 4 março, 2014, de: http://acervo.folha.com.br/fsp/1995/08/06/72/.

O'Neill, B. (2011). A critique of politically correct language. The independent review, 16 (2), 279-291.

Pondé, L. (2012). Guia politicamente incorreto da filosofia. São Paulo: Leya.

Possenti, S. (1995). A linguagem politicamente correta e a análise do discurso. Revista de estudos da linguagem, 4(2), 123-140. 
Queiroz, A. (2004). Politicamente correto e direitos humanos. Brasília: Secretaria Especial dos Direitos Humanos. Recuperado em 23 fevereiro, 2014, de: http://www.dhnet.org.br/dados/cartilhas/a_pdf_dht/cartilha_po liticamente_correto.pdf.

Rajagopalan, K. (2000). Sobre o porquê de tanto ódio contra a linguagem "politicamente correta". In F. Silva \& H. Moura (Orgs.). O direito à fala: a questão do preconceito lingüístico (pp. 93-102). Florianópolis: Insular.

Redação Terra (2005, maio 5). Cartilha do politicamente correto é ridicularizada [Versão eletrônica]. Terra. Recuperado em 1 março, 2014, de: http://noticias.terra.com. br/brasil/noticias/0,,OI526576-

El 1194,00-

Cartilha+do+politicamente+correto+e+ridicularizada.html.

Ribeiro, R. (1992, março 29). Aqui não tem PC [Versão eletrônica]. Folha de São Paulo - Ilustrada, p. 5-3. Recuperado em 2 março, 2014, de: http: //acervo. folha. com. br/fsp/1992/03/29/21/.

Rodden, J. (2010). The perversity of "diversity". Society, 47, 3-5.

Scalzo, F. (1994, março 20). Claude Lefort ataca a crítica conformista [Versão eletrônica]. Folha de São Paulo - Mais!, p. 6-9. Recuperado em 4 março, 2014, de: http://acervo. folha.com. br/fsp/1994/03/20/72/.

Schwartsman, H. (2005, maio 12). Tributo à estultice [Versão eletrônica]. Folha de São Paulo. Recuperado em 1 março, 2014, de:

http://www1.folha.uol.com.br/folha/pensata/helioschwartsman/ ult510u356109.shtml.

Soares, L. (1998). Politicamente correto: o processo civilizador segue seu curso. In P. Pinto, C. Magro, E. Santos \& L. Guimarães (Orgs.). Filosofia analítica, pragmatismo e ciência (pp. 217238). Belo Horizonte: Editora UFMG.

\section{Endereço para correspondência}

\section{Amadeu de Oliveira Weinmann}

Universidade Federal do Rio Grande do Sul

Departamento de Psicanálise e Psicopatologia - Instituto de Psicologia

Av. Montenegro, 186 / 602, CEP 90460-160, Porto Alegre - RS, Brasil

Endereço eletrônico: weinmann.amadeu@gmail.com

Fábio Vacaro Culau

Universidade Federal do Rio Grande do Sul

Rua Ramiro Barcelos, 2600 sala 132, CEP 90035-003, Porto Alegre - RS, Brasil

Endereço eletrônico: fabioculau@gmail.com

Recebido em: 29/04/2014

Reformulado em: 15/06/2014

Aceito em: 31/07/2014 
Amadeu de Oliveira Weinmann, Fábio Vacaro Culau

Notas sobre o politicamente correto

\section{Notas}

* Professor Doutor do Departamento de Psicanálise e Psicopatologia do Instituto de Psicologia da Universidade Federal do Rio Grande do Sul.

** Licenciado em História e estudante de Psicologia da Universidade Federal do Rio Grande do Sul. 